\title{
Study on Mechanical Features of Brazilian Splitting Fatigue Tests of Salt Rock
}

\author{
Weichao Wang, ${ }^{1,2}$ Mengmeng Wang, ${ }^{1}$ and Xiliang Liu ${ }^{1}$ \\ ${ }^{1}$ School of Civil Engineering, Henan Polytechnic University, Jiaozuo, Henan 454000, China \\ ${ }^{2}$ Henan Colleges and Universities Deep Mine Construction Key Discipline Open Laboratory, Jiaozuo, Henan 454000, China \\ Correspondence should be addressed to Weichao Wang; 376194856@qq.com
}

Received 12 January 2016; Revised 24 March 2016; Accepted 26 May 2016

Academic Editor: Serji N. Amirkhanian

Copyright (c) 2016 Weichao Wang et al. This is an open access article distributed under the Creative Commons Attribution License, which permits unrestricted use, distribution, and reproduction in any medium, provided the original work is properly cited.

\begin{abstract}
The microtest, SEM, was carried out to study the fracture surface of salt rock after the Brazilian splitting test and splitting fatigue test were carried out with a servo-controlled test machine RMT-150B. The results indicate that the deviation of using the tablet splitting method is larger than that of using steel wire splitting method, in Brazilian splitting test of salt rock, when the conventional data processing method is adopted. There are similar deformation features in both the conventional splitting tests and uniaxial compression tests. The stress-strain curves include compaction, elasticity, yielding, and failure stage. Both the vertical deformation and horizontal deformation of splitting fatigue tests under constant average loading can be divided into three stages of "looseningtightness-loosening." The failure modes of splitting fatigue tests under the variational average loading are not controlled by the fracturing process curve of the conventional splitting tests. The deformation extent of fatigue tests under variational average loading is even greater than that of conventional splitting test. The tensile strength of salt rock has a relationship with crystallization conditions. Tensile strength of thick crystal salt rock is lower than the bonded strength of fine-grain crystals.
\end{abstract}

\section{Introduction}

Geotechnical engineering is often subjected to cyclic loading. The mechanical characteristic of the surrounding rock under cyclic loading is one of the important factors that affect fatigue life of geotechnical engineering. Therefore, the fatigue failure mechanism of the rock is of great significance to the long-term stability and safety of rock mass, which has been widely given concern for domestic and foreign scholars.

Lots of material fatigue failure tests for rocks were carried out by the domestic and foreign scholars [1-6]. They found that the fatigue life is related to the maximum stress limit, loading waveforms, and stress amplitudes. Investigation on fatigue failure process of white sandstone under cyclic loading indicates that the maximum stress limit and amplitude are the main factors affecting the fatigue failure process [1]; the strain rate is in negative correlation with the fatigue life and showing a rule of exponential curve. Zhu et al. carried out uniaxial cyclic impact compression test for granite through using the improved large diameter of Higginson (SHPB) test system and analyzed the mechanical properties under cyclic impact load and the law of energy absorption [2]. Su et al. carried out splitting fatigue failure tests on the sandstone. The results show that the fatigue limit load ratio and tensile fatigue strength are in negative correlation with cyclic number [3]. Erarslan and Williams had studied splitting test on rocks of preexisting crack and analyzed the fracture mode of the fatigue damage [4].

Salt rock can be used as underground storage medium of oil, gas, and other strategic energy with its advantages of low permeability and damage self-repairing [7]. At present, our country is gradually increasing the construction of salt dome energy storage. Domestic scholars also have carried out many research projects. Li et al. had studied the fatigue strength, deformation, and damage characteristics of salt rock under uniaxial cyclic loading [8]. The results show that the cyclic fatigue failure process of rock salt is also controlled by static full curve. Yang et al. found that, in the uniaxial cyclic loading tests of rock salt, deformation modulus of linear portion displayed a general ascending trend with the increase of load level, whether it is unloaded or loaded [9]. $\mathrm{Ma}$ et al. considered that the upper limit stress threshold 
TABLE 1: Brazilian split test results of rock salt.

\begin{tabular}{|c|c|c|c|c|c|c|}
\hline Grouping & Serial number & Test method & $\mathrm{D} / \mathrm{mm}$ & $L / \mathrm{mm}$ & $P / \mathrm{kN}$ & $R_{t} / \mathrm{MPa}$ \\
\hline \multirow{6}{*}{ Group one } & BJA-1 & Plate & 50.60 & 40.70 & 6.412 & 2.004 \\
\hline & BJA-2 & Plate & 50.32 & 42.16 & 6.642 & 1.993 \\
\hline & BJA-3 & Plate & 50.80 & 40.38 & 6.602 & 2.049 \\
\hline & BJA-4 & Plate & 50.62 & 44.80 & 7.340 & 2.061 \\
\hline & BJA-5 & Plate & 50.78 & 46.00 & 7.102 & 1.939 \\
\hline & Mean & & & & 6.820 & 2.009 \\
\hline \multirow{8}{*}{ Group two } & BJC-4 & Steel wire & 50.60 & 40.20 & 5.716 & 1.789 \\
\hline & BJD-1 & Steel wire & 50.40 & 44.90 & 5.096 & 1.434 \\
\hline & BJE-1 & Steel wire & 50.52 & 45.90 & 6.072 & 1.667 \\
\hline & BJF-1 & Steel wire & 50.30 & 44.20 & 4.286 & 1.227 \\
\hline & BJF-2 & Steel wire & 50.70 & 43.24 & 6.452 & 1.874 \\
\hline & ${ }^{*} \mathrm{BJH}-1$ & Steel wire & 50.70 & 45.70 & 3.712 & 1.020 \\
\hline & BJH-2 & Steel wire & 50.80 & 47.00 & 6.758 & 1.802 \\
\hline & Mean & & & & 5.73 & 1.632 \\
\hline
\end{tabular}

* The discrete results, not involved in calculation.

of three-axis cyclic deformation failure is $89 \% \sim 80 \%$, which is inferred through experiments indirectly [10]. They also found that the strain hardening characteristics in secondary compression of salt rock are more remarkable than that of the first compression.

The stress field of surrounding rock is changing constantly in the operation of salt cavern storage due to the injection-production cycle load. However, the study of the above scholars mostly concerned the uniaxial and triaxial fatigue tests of the salt rock and lack of research on mechanical properties of the salt rock under the tension compression cyclic loading. Of course, the rock mass is mostly in biaxial or triaxial state of stress and rarely in unidirectional tensile failure in the engineering practice. However, there are large amounts of damage starting from the local tensile damage. Therefore, in order to analyze tensile fatigue strength and deformation characteristics of salt rock, this paper conducted experiments including Brazilian splitting test, constant average load splitting fatigue test in which we use constant frequency and constant amplitude sine wave individually, and variable mean load splitting fatigue test. Conclusions of this paper can be used as part of experiences and reference providing for the gas storage operations in salt caverns.

\section{Experimental Method}

In order to reduce the dispersion degree of the test results, this experiment used the high purity Himalaya salt rock, which has the advantage of macroscopic uniform density, uniform color, and compact structure. The specimens were cut by using dry sawing and grinding method in the manufacturing process of the specimen, coring drilling core with a diameter of $50 \mathrm{~mm}$, because the salt rock is soft and water-soluble relatively, and the rock salt specimens were processed into a cylinder finally. The thickness-diameter ratio of splitting test method is $0.5-1.0$ and end face parallelism is $\pm 0.02 \mathrm{~mm}$, which meet the requirements of determination method. The

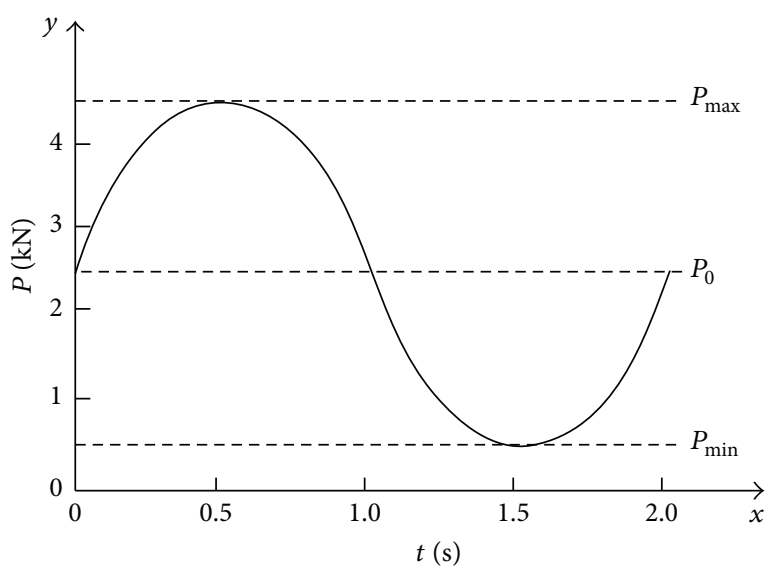

FIGURE 1: Waveform of Brazilian split fatigue.

specific dimensions of the specimens have been shown in Table 1.

RMT-150B rock mechanics test system is adopted which was developed by the Institute of Rock and Soil Mechanics, Academia Sinica, Wuhan. This system can be used for different wave frequency and amplitude fatigue test. There is much difference in tensile strength of rock because of the different compression method [11]. The conventional split test was carried out firstly in order to determine the tensile strength of salt rock exactly, using two kinds of compression method. One method is the steel wire pad loading splitting method, called the steel wire splitting method; the diameter of the steel wire is $2 \mathrm{~mm}$. The other method for the use of a steel pad is directly loaded, known as the plate split method. Vertical direction $(y)$ and horizontal direction $(x)$ are placed on the sensor to measure the compression and tensile deformation. Then, the fatigue test of constant mean load and variable mean load was carried out, and the parameters of splitting fatigue test were set up according to the conventional split test; the fatigue load waveform was shown in Figure 1. 


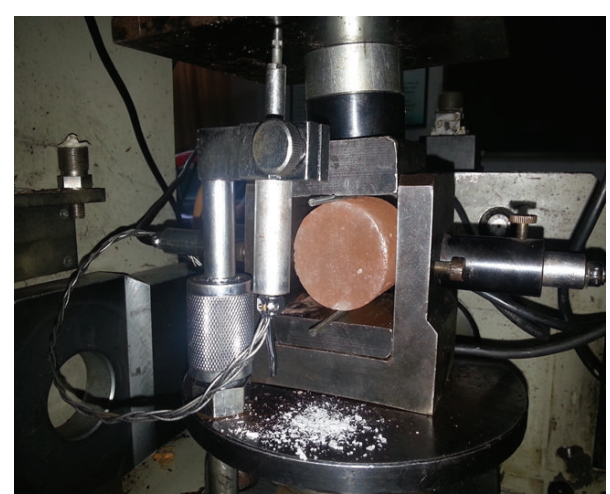

FIgUre 2: Photo of salt rock specimens on loading.

The upper and the lower limit and the average load were represented by $P_{\max }, P_{\min }$, and $P_{0}$, respectively; the amplitude $\Delta P=P_{\max }-P_{\min }$ in Figure 1.

According to the loading mode of Figure 2, the tensile strength of the conventional split test specimen according to national standard [12] can be expressed as

$$
R_{t}=\frac{2 P}{\pi D L},
$$

where $R_{t}$ represents the rock tensile strength, $L$ is the thickness of the specimen, $D$ is the diameter of the specimen, and $P$ is the failure load of the specimen.

\section{Analysis of the Results of the Conventional Splitting Test}

The conventional split test of salt rock was carried out firstly for setting up the parameters of fatigue test reasonably, and the actual loading condition is shown in Figure 2, and the loading method was carried out according to the force control, and loading rate was $0.05 \mathrm{kN} / \mathrm{s}$. The results of conventional splitting test of salt rock are shown in Table 1 , where $P$ is a regular splitting failure load and $R_{t}$ is the tensile strength of the specimens of splitting test. We can get from the table that the failure loads of splitting test of the first group, 5 specimens, are $6.412 \sim 7.34 \mathrm{kN}$; the average value is $6.82 \mathrm{kN}$. The tensile strength is 1.939 2.061 MPa according to formula (1), and the average value is $2.009 \mathrm{MPa}$. Although the specimens have the advantage of macroscopic uniform density and uniform color among the 7 specimens of the second group, the test results show certain dispersion. Specimen BJH-1 is not added in the average calculation because it has the unusual failure load and the tensile strength, larger dispersion. Splitting failure loads of the second group are $4.286 \sim 6.758 \mathrm{kN}$; the average value is $5.73 \mathrm{kN}$. The tensile strength is $1.227 \sim 1.802 \mathrm{MPa}$, and the average value is $1.632 \mathrm{MPa}$. The average value of the first group is $23.1 \%$ higher than the second group compared with the above experimental data. The results of the steel wire splitting test were generally less than the direct loading test, and the average value of the results of the steel wire splitting method is significantly smaller than that of the plate splitting method. This paper adopts the method of steel wire loading in the splitting fatigue test through the theoretical analysis of the results of the fourth section.

The curves of vertical deformation-time and load-deformation of salt rock specimen, under the steel wire splitting method, are shown in Figure 3. In the picture, vertical compression deformation is positive, represented by $Y$; the tensile deformation in the horizontal direction is negative, represented by $X$.

It can be seen from Figure 3(a) that the deformation characteristics of conventional split failure are similar to the sandstone splitting failure, which is divided into four stages: compaction, elasticity, yielding, and failure [3]. The main feature of the compaction stage is slightly concave in the initial position, and the main reasons are listed as follows. The first one is that the specimen itself has flaw (voids and cracks) in compaction process, and the specimen contact with steel wire is particularly more obvious. The second one is that the specimen is not smooth enough of the surface, and local deformation occurs in the contact with the steel wire. In the elastic stage, the deformation increases linearly as the load increases, exhibiting elastic characteristics. In the yield stage, the curve mainly performs nonlinear feature near the peak but slightly convex phenomenon. In the failure stage, the specimen is destroyed suddenly when the load reaches the ultimate bearing capacity; meanwhile there is still a certain amount of deformation. This characteristic is different significantly from the failure stage of sandstone [3]. The reason may be that the salt rock is soft and stress concentration exists at the loading point and the wire cut-in before the specimen breaking out. The fairly large concaveupward curve in the initial stage of specimen BJD-1 is more likely caused by the surface roughness. However, the obvious convex phenomenon appearing in specimen BJF2 is more likely related to the error caused by the relative movement between the sensor and the plate in the initial pressure. These four stages can also be seen in Figure 3(b). The vertical deformation increases linearly with the increase of the loading time after compaction stage, and then the vertical deformation increases gradually at the yield stage, the specimen fractures abruptly, and the vertical deformation increases suddenly when load reaches the failure value.

\section{Theoretical Analysis of Conventional Splitting Test}

The method of using the Brazilian disc splitting test to obtain the tensile strength of rocks materials indirectly is recommended by the international Institute of Rock Mechanics (ISRM), whose theoretical basis is that Brazil disc can be simplified as an analytic solution of the elastic mechanics of the plane strain problem which is under the symmetrical and constringent line load [13]. As shown in Figure 4(a), D is the diameter of the disc which is subjected to concentrated load of $p(p=P / L)$. The stress state of one point $M(x, y)$ in the disc is

$$
\sigma_{x}=\frac{2 P}{\pi L}\left(\frac{\sin ^{2} \theta_{1} \cos \theta_{1}}{r_{1}}+\frac{\sin ^{2} \theta_{2} \cos \theta_{2}}{r_{2}}\right)-\frac{2 P}{\pi D L},
$$



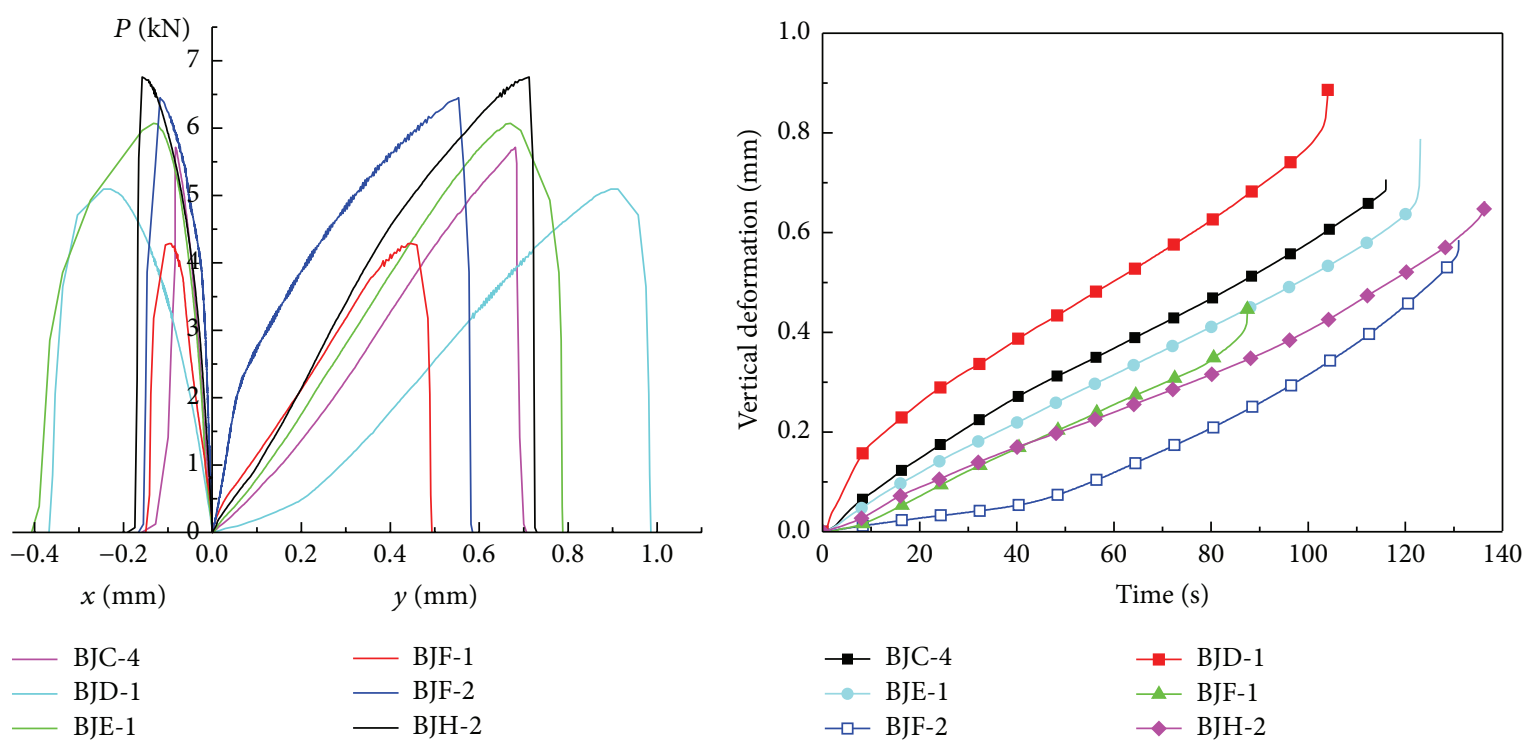

(b) Vertical deformation-time curve

(a) Fracturing load-deformation curve

Figure 3: Curve of the wire split tests.

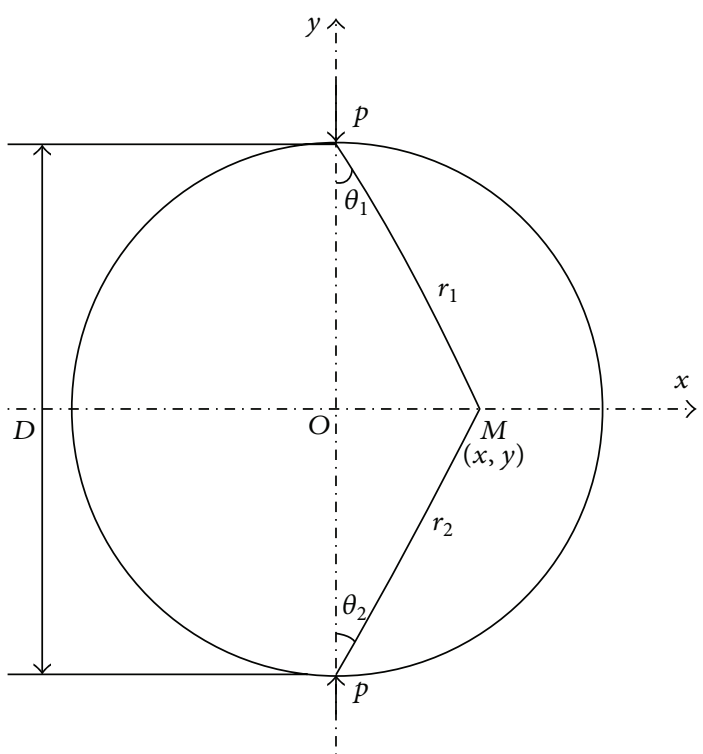

(a) Steel wire loading method

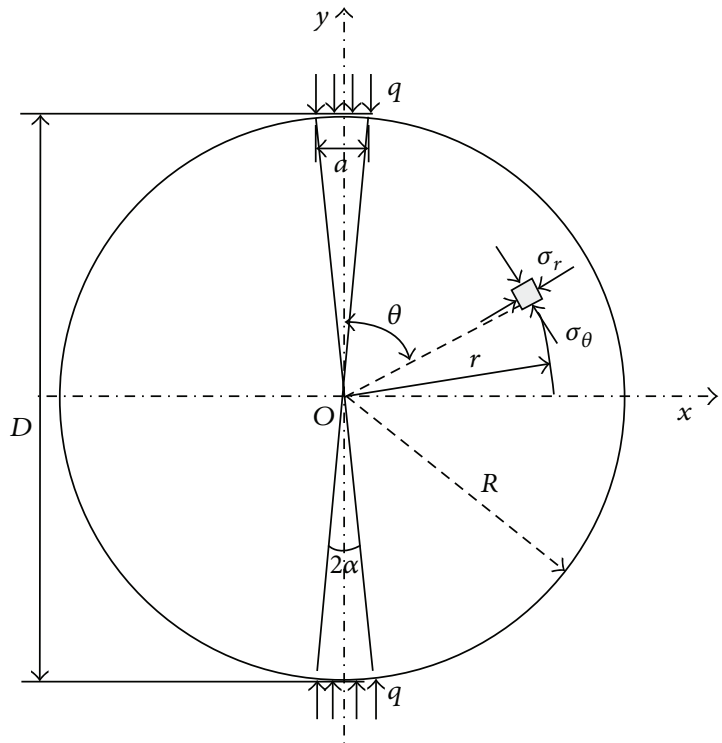

(b) Plate loading method

Figure 4: Sketch map of Brazilian disk test.

$$
\begin{aligned}
\sigma_{y} & =\frac{2 P}{\pi L}\left(\frac{\cos ^{3} \theta_{1}}{r_{1}}+\frac{\cos ^{3} \theta_{2}}{r_{2}}\right)-\frac{2 P}{\pi D L}, \\
\tau_{x y} & =\frac{2 P}{\pi L}\left(\frac{\sin \theta_{1} \cos ^{2} \theta_{1}}{r_{1}}-\frac{\sin \theta_{2} \cos ^{2} \theta_{2}}{r_{2}}\right),
\end{aligned}
$$

where parameter $D$ is disc diameter, $L$ is the thickness of the disk, and $P$ is breaking load. $\theta_{1}$ and $\theta_{2}$ are positive when point $M$ is in the right side of disc; on the contrary, $\theta_{1}$ and $\theta_{2}$ are negative.
In the center of the circle, $\theta_{1}=\theta_{2}=0, r_{1}=r_{2}=D / 2$, substituting into formulas (2) and (3), we can get tensile stress and compressive stress of the center of specimen:

$$
\begin{aligned}
& \sigma_{y}=\frac{6 P}{\pi D L}, \\
& \sigma_{x}=-\frac{2 P}{\pi D L} .
\end{aligned}
$$

Thus, it can be found that the compressive stress of center is 3 times the tensile stress. The compressive strength of rock 
materials is much higher than that of tensile strength; therefore, the cracks of rock in the center are aroused by tensile stress. In the loading process of the actual test, although there are errors when using the wire splitting method, the alloy steel wire can be considered to transmit line load similarly. The results can be calculated according to formula (6). The strength of salt rock is lower compared with the granite and other hard rock because it is soft rock. When using the plate splitting method, the plastic deformation is generated at the contact place of the specimen and the loading plate in the loading process and the line load turns into gradually surface load. At this moment, the force of the disc is not point load of the vertical direction as shown in Figure 4(a) but the line load as shown in Figure 4(b). The length of line load is related to the platform angle $2 \alpha$. Therefore, the failure load was expressed as

$$
q=\frac{P}{a L}
$$

Now, if we use formula (1) to calculate the tensile strength it will lead to a larger error inevitably. That is, the cause of the average tensile strength of the first group is $23.1 \%$ higher than that of the second group. To solve this problem, the author considers that we can try to make use of the Griffith strength criterion, for platform disc, and when the tensile stress reaches $\sigma_{G}$, the specimens are damaged:

$$
\sigma_{G}=\sigma_{t}=-\frac{\left(\sigma_{\theta}-\sigma_{r}\right)^{2}}{8\left(\sigma_{\theta}+\sigma_{r}\right)}
$$

where $\sigma_{G}$ represents the stress of the Griffith strength criterion to calculate, $\sigma_{t}$ is tensile strength, and $\sigma_{\theta}$ and $\sigma_{r}$ reflect, respectively, the maximum and minimum principal stress. The formula for calculating the tensile strength is given in document [14] as follows:

$$
\begin{aligned}
\sigma_{G} & =-\frac{k 2 P_{c}}{\pi D t} \\
k & =\frac{\left(2 \cos ^{3} \alpha+\cos \alpha+\sin \alpha / \alpha\right)^{2}}{8(\cos \alpha+\sin \alpha / \alpha)},
\end{aligned}
$$

where $P_{c}$ represents the critical load which is the maximum load measured in the test, parameter $D$ is the diameter, parameter $t$ is the specimen thickness, and $k$ is the coefficient of the platform scale. The results of this calculation method on the test data will be listed in another paper due to space limitations of this paper.

\section{Analysis of the Results of Brazilian Split Fatigue Test}

5.1. Constant Load Fatigue Test. Based on the above analysis, the wire splitting method was carried out in splitting fatigue test. The constant load fatigue test was carried out firstly in order to clarify the deformation and failure characteristics of the whole process of salt rock in the splitting fatigue test. Set the average load of the splitting fatigue test horizontal as

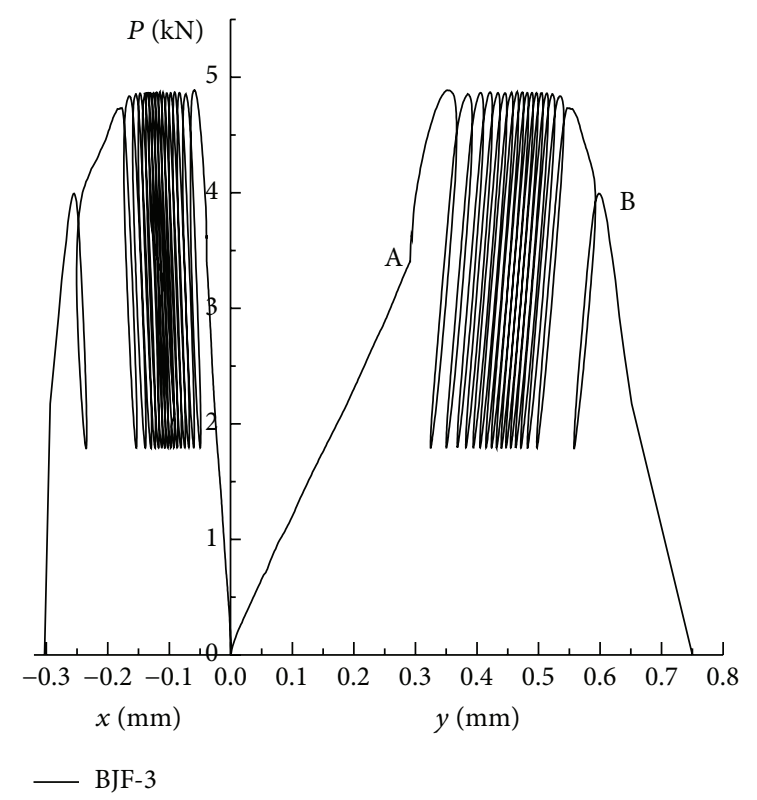

FIGURE 5: Load-deformation curves of Brazilian split fatigue tests of constant average load.

$3.4 \mathrm{kN}$, and the upper limit load is $4.86 \mathrm{kN}$, the upper limit load (stress) ratio is about 0.85 , the lower limit load is $1.79 \mathrm{kN}$, and the lower limit load (stress) ratio is about 0.31 according to the results of conventional splitting test. Acquisition system was set to record 1 hysteresis loop when the deformation is more than $0.0125 \mathrm{~mm}$ to avoid load-deformation curves of fatigue test too dense.

Judging from the test results, the discreteness of splitting fatigue life of the salt rock is relatively large, but it has obvious phased characteristics from the view of cumulative evolution of the plastic deformation and deformation development. The following analysis will take specimen BJF-3 as an example. Figure 5 shows the whole process of load-deformation curves of specimen BJF-3.

It can be seen that the load-vertical deformation curve is divided into two parts from Figure 5. The first part of the curve (OA section) is a static loading stage, the load increases at the constant rate of $0.05 \mathrm{kN} / \mathrm{s}$ till the average load level, and it is a linear relationship between load and deformation. The second part of the curve ( $\mathrm{AB}$ section) is a splitting fatigue stage; the cyclic load begins with the average load level at the frequency of $1 \mathrm{~Hz}$. The curve of $\mathrm{AB}$ shows 3 obvious stages, which are sparse-dense-sparse. The first stage is the beginning stage of the cycle, the axial deformation develops rapidly, and each cycle has a more obvious deformation, which accumulates a large deformation. After a few cycles, the deformation rate tends to be stable with the increase of the cycles, which represents deformation entering the second stage, stable development stage. The development rate of strain in this stage is relatively stable and axial strain development is slow, which accounts for most of the fatigue life. The deformation rate of the specimen increases sharply with the increase of the number of cycles, which represents deformation turning into the third stage. The specimen is 
TABLE 2: Brazilian split fatigue test results of rock salt.

\begin{tabular}{|c|c|c|c|c|c|c|}
\hline Serial number & Dimension/mm & $P_{1} / \mathrm{kN}$ & Load level & $P_{\max } / \mathrm{kN}$ & $N$ & $\mathrm{M} / \mathrm{mm}$ \\
\hline BJB-4 & $50.7 \times 44.9$ & 3.0 & 4 & 5.9 & 1502 & 0.93 \\
\hline BJD-2 & $50.6 \times 42.3$ & 3.0 & 4 & 6.1 & 2000 & 0.69 \\
\hline BJD-5 & $50.6 \times 43.4$ & 3.0 & 6 & 7.1 & 2590 & 0.95 \\
\hline BJH-4 & $50.9 \times 46.6$ & 2.6 & 4 & 6.5 & 2000 & 1.15 \\
\hline BJF-4 & $50.1 \times 44.4$ & 3.4 & 5 & 7.0 & 5198 & 0.95 \\
\hline${ }^{*}:$ E-3 & $50.7 \times 37.5$ & 3.0 & 1 & 3.7 & 0 & - \\
\hline${ }^{*}:$ E-4 & $50.6 \times 41.1$ & 3.0 & 1 & 3.1 & 0 & - \\
\hline
\end{tabular}

${ }^{*}$ The discrete results, not involved in calculation.

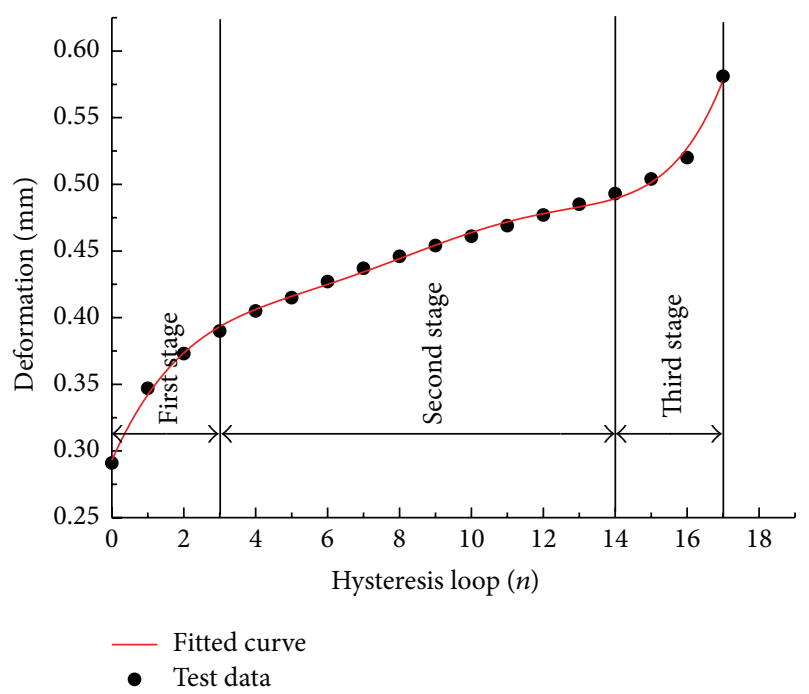

FIGURE 6: Relationship between hysteresis loop and deformation.

suddenly destroyed, which experiences a very short time and the number of cycles is very small. The feature of this curve is similar to the feature of cyclic compression of white sandstone [1]. From the failure mechanism, the elastic and plastic deformation of the specimen is generated at each time of the cyclic loading, plastic deformation is due to internal stress of specimens changes caused by injury, and plastic deformation accumulated by hysteresis loop gradually increases with the cycle number, which finally causes the rapid destruction of the specimen. It is not difficult to find that the loadhorizontal deformation curve is similar to that of the vertical deformation curve from Figure 3, and the three stages show obvious characteristics of the sparse-dense-sparse stages. This characteristic is obviously different from the horizontal deformation of the red sandstone under cyclic loading [15].

According to Figure 6 of the original curve data, we calculate the deformation difference of each hysteresis loop between the start and end point that is the deformation quantity generated for each of the hysteresis loops and draw the scattered points with the change of the number of cycles on Figure 6. In Figure 6, it is clear that the whole process of fatigue deformation can be divided into three stages, confirming the characteristics of the above three stages.
5.2. Variable Mean Load Splitting Fatigue Test. In the process of variable mean load splitting fatigue test, the amplitude of cyclic loading kept constant and started loading 500 times when the initial average load level reaches $P_{1}$; after that, the load of the 500 cycles, adding $0.5 \mathrm{kN}$ to average load, was loaded. Then, each of the 500 cycles of cyclic loading added $0.5 \mathrm{kN}$ to average load until the specimen was destroyed completely. Moreover, BJF-4 was loaded 3100 times at load level $P_{1}$ for comparing with other specimens. The results of variable mean load splitting fatigue test for salt rock are as shown in Table 2, where $P_{1}$ is the first level load value, $P_{\max }$ represents the maximum load value in the complete cycling periods before the test failure, $N$ is the total number of cycles, and $M$ is the total deformation of the vertical direction when the specimen is destroyed. As can be seen from Table 2, the total number $N$ of cyclic loading on each specimen has relatively large dispersion; the average value is $6.52 \mathrm{kN}$ and the average deformation value is $0.93 \mathrm{~mm}$. The hysteresis loop number and deformation have obvious regularity from each of the 500 cycles. The value of per-load level, the number of hysteresis loop, and the deformation are as shown in Table 3 for more accurate analysis, in which $P_{i}(i=$ 1 6) represents average load of the grade $i, T_{0}$ is the cycle number of horizontal loading and unloading of the first load grade, $N_{i}(i=1 \sim 6)$ represents hysteresis loop number forming in the load process of grade $i$, and $M_{i}(i=1 \sim 6)$ represents vertical deformation in the load process of grade $i$. Specimen BJF-4 was loaded and unloaded 3000 times at the first load level. The hysteresis loop number and deformation amount at the first load level per 500 times are shown in Table 3 at the last row in order to compare study handily.

The vertical deformation-load curve of test specimen BJD-2 is shown in Figure 7. As can be taken from Figure 7 and Table 3, cyclic loading loads 500 times at the first load level and the curve goes through the first stage of the three stages of "sparse-dense-sparse", resulting in larger deformation. Improving the average load level and load 500 times, the deformation is less than the first level. It remains at the "dense" stage (second stage); thus, although the average load is slightly larger than the previous one, the deformation amount is less than the first stage. The deformation of each stage is gradually increasing with the gradual increase of the load level. During the last stage of the load level, the deformation increases rapidly in the course of cyclic loading, 
TABLE 3: Detailed data of Brazilian split fatigue tests of variational average load.

\begin{tabular}{lccccccccccccccccc}
\hline $\begin{array}{l}\text { Serial } \\
\text { number }\end{array}$ & $P_{1} / \mathrm{kN}$ & Amplitude/kN & $T_{0}$ & $M_{1} / \mathrm{mm}$ & $N_{1}$ & $P_{2} / \mathrm{kN}$ & $M_{2} / \mathrm{mm}$ & $N_{2}$ & $P_{3} / \mathrm{kN}$ & $M_{3} / \mathrm{mm}$ & $N_{3}$ & $P_{4} / \mathrm{kN}$ & $M_{4} / \mathrm{mm}^{2}$ & $N_{4}$ & $P_{5} / \mathrm{kN}$ & $M_{5} / \mathrm{mm}$ \\
\hline BJB-4 & 3.0 & 3 & 500 & 0.32 & 58 & 3.5 & 0.12 & 31 & 4.0 & 0.16 & 43 & 4.5 & 0.07 & 2 & - & - \\
BJD-2 & 3.0 & 3 & 500 & 0.23 & 44 & 3.5 & 0.08 & 20 & 4.0 & 0.09 & 21 & 4.5 & 0.11 & 30 & - & - \\
BJD-5 & 3.0 & 3 & 500 & 0.24 & 45 & 3.5 & 0.06 & 23 & 4.0 & 0.09 & 24 & 4.5 & 0.11 & 27 & 5.0 & 0.11 \\
BJH-4 & 2.6 & 3 & 500 & 0.29 & 53 & 3.4 & 0.10 & 28 & 4.0 & 0.11 & 30 & 4.5 & 0.14 & 40 & - & - \\
BJF-4 & 3.4 & 2.85 & 3000 & 0.37 & 78 & 4.0 & 0.07 & 17 & 4.5 & 0.08 & 22 & 5.0 & 0.11 & 29 & 5.5 & 0.15 \\
BJF-4 & 3.4 & 2.85 & 500 & 0.29 & 53 & 3.4 & 0.02 & 4 & 3.4 & 0.02 & 4 & 3.4 & 0.02 & 4 & 3.4 & 0.02 \\
\hline
\end{tabular}

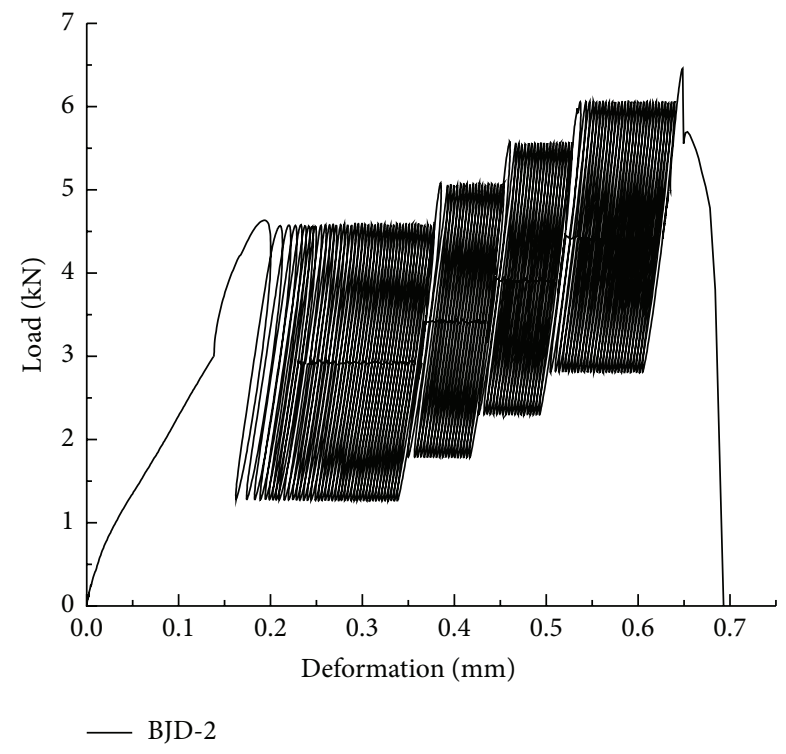

FIGURE 7: Load-deformation curves of Brazilian split fatigue tests of variational average load.

and the specimen is suddenly destroyed with the increase of deformation. Figure 8, respectively, gives the relationship between the average load level and the deformation and hysteresis loop number. From Figure 8 as can be seen, in the first level of the average load, deformation and the number of hysteresis loops become larger because it is in the beginning stage of "sparse". From the beginning of the second level of the average load, deformation, hysteresis loop number, and average load level present approximately linear growth.

Conventional splitting specimen $\mathrm{BJH}-2$ and splitting fatigue specimen BJB-4 are drawn as shown in Figure 9 together in order to compare the strength and deformation characteristics of conventional splitting with splitting fatigue test. It can be found from the graph that the maximum load value before the splitting fatigue failure is lower than that of the conventional splitting failure load. However, generally speaking, the average value of conventional splitting failure load is $5.73 \mathrm{kN}$, while the average load of fatigue failure is $6.52 \mathrm{kN}$; fatigue damage average load increases slightly instead of reducing. From the deformation we can see, the total deformation amount of specimen BJB-4 fatigue failure is not controlled by the deformation amount of conventional splitting but is significantly larger than the deformation of conventional splitting specimen BJH-2 when destroyed. For other fatigue failure specimens, only the total deformation amount of BJD-2 was less than BJH-2, so the Brazil split fatigue damage of salt rock will not be controlled by the conventional splitting of the whole process curve; this deformation characteristic is different from splitting fatigue failure of sandstone [3].

\section{Micromechanism Analysis of Cleavage Fracture}

It can be known from macroscopic view that the splitting specimen of wire steel splitting method has obvious loading indentation at load baseline, most specimens faulted in two symmetrical semicircles along the load baseline of wire steel loading bar, and there is no friction mark on the fracture surface, showing brittle failure characteristics of tensile failure. In this paper, we give a representative fracture picture of BJH-1 and BJD-5, which is shown in Figure 10. In order to be clear on the relationship between the fracture morphology and tensile strength of the salt rock, the cleavage fracture of the salt rock specimen after experiment was under electron microscope scanning to get more than 30 images under different multiple.

Although the appearance of the specimen has the same color and texture uniform from macroscopic view, the salt rock forms coarse-grain, Microtek, fine-grain, and mixed crystal salt rock by the role of compaction, cementation and dissolution, and so forth in the digenetic stages. Many factors such as microcrack and impurity content affect the tensile strength of salt rock, but the crystallization condition of salt rock is also an important factor.

The microscopic fracture modes of rocks mainly have transgranular fracture and intergranular fracture from the micro perspective view. The fracture can be divided into cleavage fracture, intergranular fracture, micropore aggregation fracture, and either of the couplings. The tensile fracture micromechanisms of rock materials include nine kinds of river pattern, stepped pattern, Lingui form pattern, herringbone pattern, rootlike patterns, axis micro pits and triangular craterlike patterns, grain boundary cracks pattern, grain boundary and intergranular fracture pattern, and intergranular fracture pattern [16]. The area of Figure 10 after scanning electron microscope is shown in Figure 11. The fracture scanning area of specimen BJD-5 presents random grain boundary fracture pattern of self-similarity on fracture surface, and the contact area is larger, having 


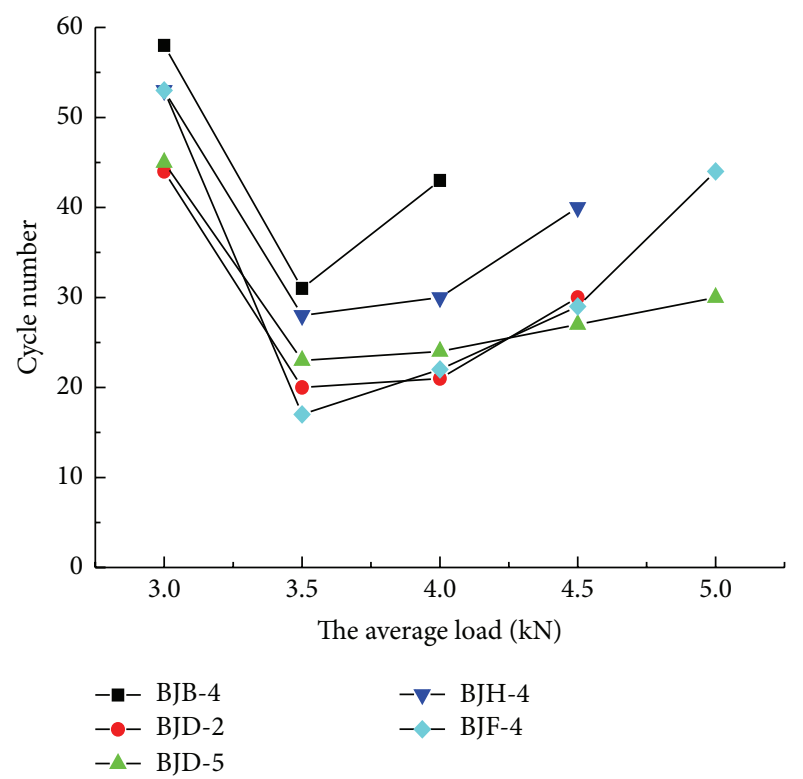

(a) Relation between cycle number and deformation

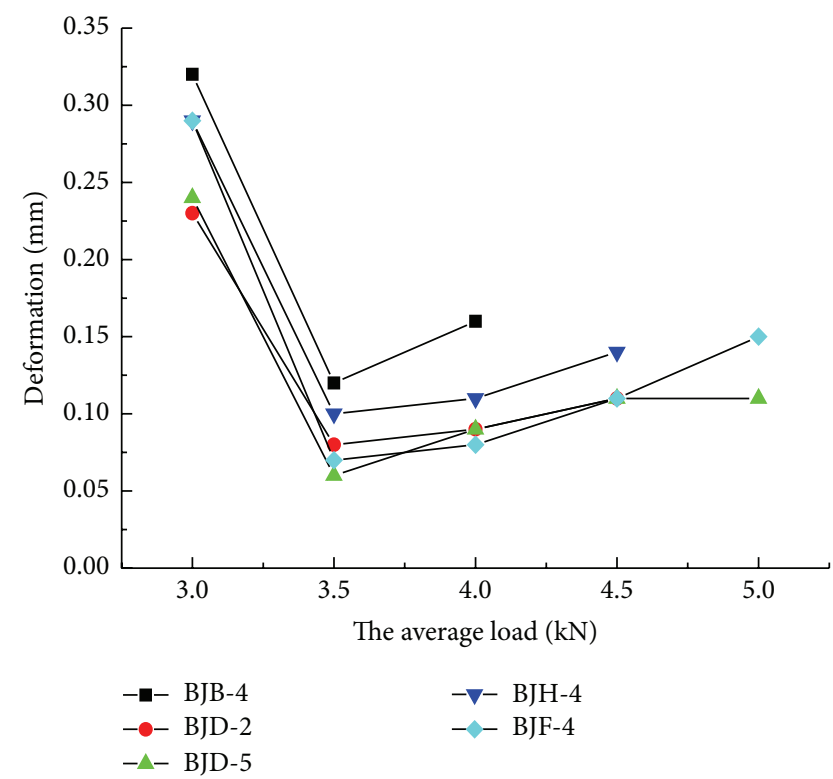

(b) Relation between average load and deformation

FIGURE 8: Deformation law along with the average load.

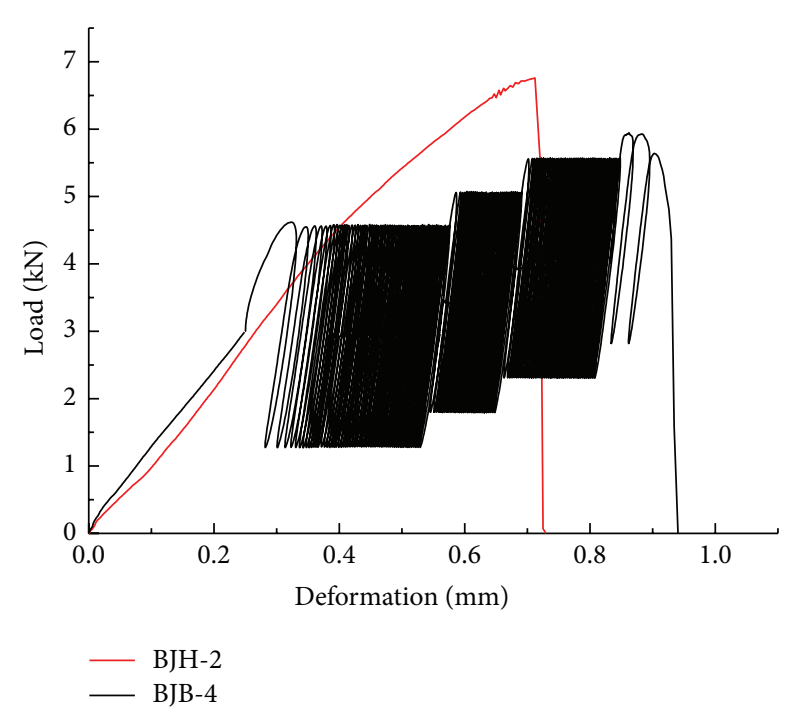

FIGURE 9: Contrast figure of conventional split and split fatigue.

more intergranular fracture characteristics, observing the other fracture morphology of the specimen, accompanied by a small amount of coupling of transgranular fracture. On the fracture scanning area of specimen $\mathrm{BJH}-1$, the fracture surface of the specimen forms irregular steps and the contact area of the fracture surface is very small, showing distinct transgranular fracture characteristics, observing the other fracture morphology of the specimen, following that with a small amount of coupling of intergranular fracture. We consider that the crystallization of salt rock affects the tensile strength of the salt rock, and the tensile strength is relatively large when fine crystal specimen is mainly based on intergranular fracture and accompanied by a small amount of transgranular fracture, and the tensile strength of the mixed crystal was relatively small, when the coarse grain of mixed crystal specimen is mainly based on the transgranular fracture and accompanied by a small amount of intergranular fracture. However, generally, the bond strength between grains is generally lower than that of their own for the multiple grains materials of rock. The conclusion above is not contradictory to the common sense because the mixed crystal salt rock contains a small amount of coarse crystal; the tensile strength of the coarse crystal is lower than that bond strength of the fine grain; from the macro side, the tensile strength of coarse crystal of the salt rock containing coarse crystal is lower than that of the pure fine crystal salt [17]. Of course, the factors that affect the tensile strength of salt rock also have many others, for example, microcrack and salt rock inclusion; the conclusion still needs to be studied in the following experiments.

\section{Conclusion}

(1) The load-deformation curve of variable mean load splitting fatigue test is not controlled by the conventional splitting process curve, and deformation amount of damage is even greater than the conventional split test.

(2) In the variable mean load splitting fatigue test, the amounts of deformation and hysteresis loops are larger because deformation lies in the beginning stage of "sparse" under the first stage of average loading. The deformation, hysteresis loop number, and average load level present approximately linear growth from the beginning of the second average load stage. 


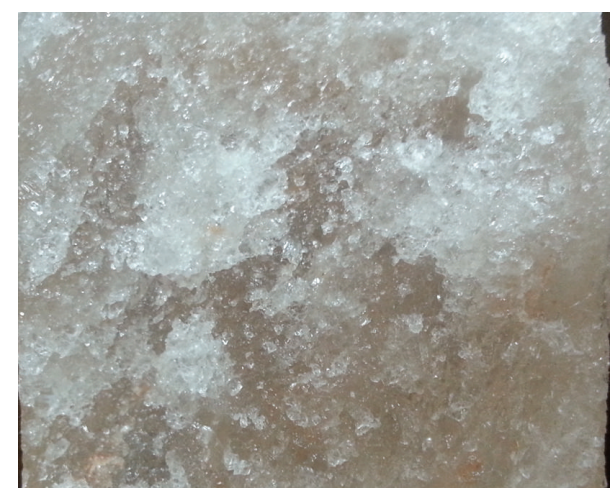

(a) Fracture appearance of specimen BJD-5

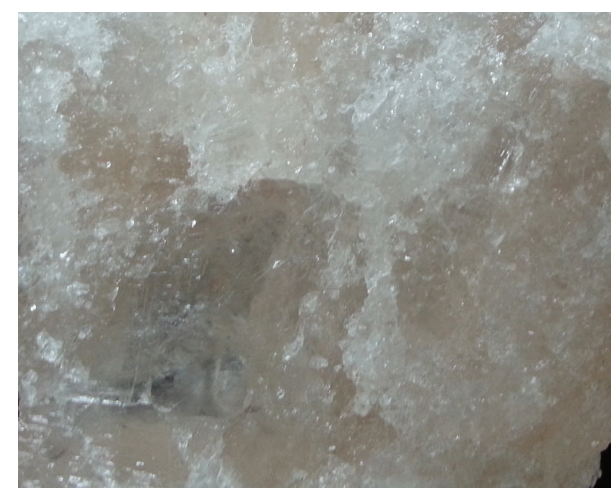

(b) Fracture appearance of specimen BJH-1

FIgURE 10: Fracture morphology of salt rock specimen.

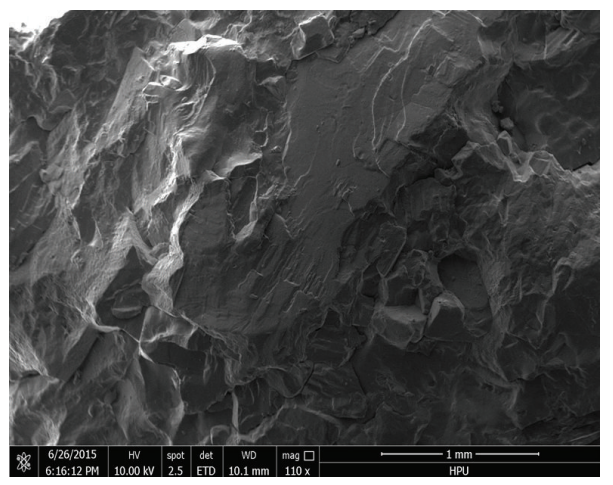

(a) SEM image of BJD-5

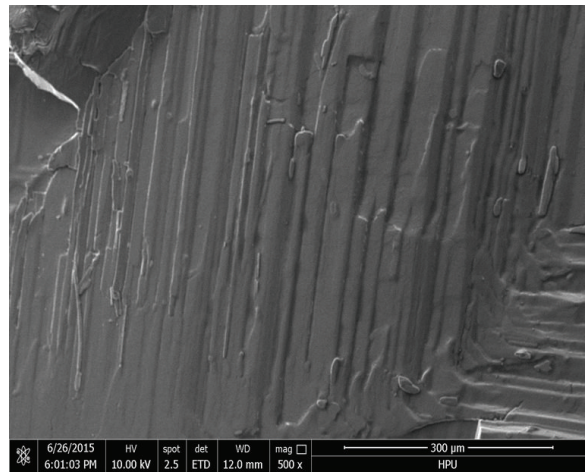

(b) SEM image of BJH-1

FIGURE 11: Comparison of SEM images between BJD-5 and BJH-1.

(3) The load-vertical deformation curve of the splitting fatigue failure of the constant average load includes three stages of "sparse-dense-sparse", respectively, cycle initial stage, the deformation and stability development stage, and deformation acceleration stage. The load-horizontal deformation curve also includes three stages of "sparse-dense-sparse", which is obviously different from the red sandstone.

(4) For a soft rock such as salt rock, the direct loading process caused relatively the larger deformation of the specimens in the process of split test. The failure status is similar to platform disk splitting failure status; hence, the results through the conventional data processing method have larger error. The split test was carried out using the method of wire splitting, and the results are relatively more accurate than the conventional data method.

(5) The deformation characteristics of conventional split test are similar to that of uniaxial compression, which is divided into 4 stages that include compaction, elasticity, yield, and failure.

\section{Competing Interests}

The authors declare that they have no competing interests.

\section{Acknowledgments}

Financial support for this work, provided by the Fundamental Research Funds for the Universities of Henan Province (Project no. NSFRF140145) and Opening Laboratory for Deep Mine Construction, Henan Polytechnic University (Project no. 2014KF-06), is gratefully acknowledged.

\section{References}

[1] C. Feng, X. Wu, D. Ding, and Y. Wu, "Investigation on fatigue characteristics of white sandstone under cyclic loading," Chinese Journal of Rock Mechanics and Engineering, vol. 28, no. 1, pp. 2749-2754, 2009.

[2] J. J. Zhu, X. B. Li, F. Q. Gong, and S. M. Wang, "Experimental study of dynamic characteristics and damage model for rock under cyclical impact compressive loads," Chinese Journal of Geotechnical Engineering, vol. 32, no. 5, pp. 657-662, 2010.

[3] C. Su, S. Zhang, and X. Tang, "Experimental research on deformation and strength characteristics in process of Brazilian split 
fatigue failure of sandstone," Chinese Journal of Rock Mechanics and Engineering, vol. 32, no. 1, pp. 41-48, 2013.

[4] N. Erarslan and D. J. Williams, "Mechanism of rock fatigue damage in terms of fracturing modes," International Journal of Fatigue, vol. 43, pp. 76-89, 2012.

[5] X. U. Jiang, L. I. Shu-chun, X.-J. Tang, Y.-Q. Tao, and H.-W. Yang, "Rock fatigue damage evolution based on acoustic emission," Journal of University of Science and Technology Beijing, vol. 31, no. 1, pp. 19-24, 2009.

[6] Z.-D. Zhu, L.-Z. Sun, and M.-Y. Wang, "Damping ratio experiment and mesomechanical analysis of deformation failure mechanism on rock under different frequency cyclic loadings," Rock and Soil Mechanics, vol. 31, supplement 1, pp. 8-12, 2010.

[7] J.-F. Liu, J. Xu, C.-H. Yang, and Z.-M. Hou, "Mechanical characteristics of tensile failure of salt rock," Chinese Journal of Geotechnical Engineering, vol. 33, no. 4, pp. 580-586, 2011.

[8] Y. P. Li, W. Liu, C. H. Yang, and J. J. K. Daemen, "Experimental investigation of mechanical behavior of bedded rock salt containing inclined interlayer," International Journal of Rock Mechanics and Mining Sciences, vol. 69, no. 5, pp. 39-49, 2014.

[9] C. H. Yang, W. J. Jing, J. J. K. Daemen, G. Zhang, and C. Du, "Analysis of major risks associated with hydrocarbon storage caverns in bedded salt rock," Reliability Engineering \& System Safety, vol. 113, pp. 94-111, 2013.

[10] L. J. Ma, X. Y. Liu, H. F. Xu et al., "Deformation and strength properties of rock salt subjected to triaxial compression with cyclic loading," Chinese Journal of Rock Mechanics and Engineering, vol. 32, no. 4, pp. 849-856, 2013.

[11] M. C. He, J. C. Hu, W. Xiong, and C. Y. Liu, "Splitting test and analysis of rock tensile strength," Mining $R \& D$, vol. 25 , no. 2, pp. 12-16, 2005.

[12] The National Standards Compilation Group of Peoples Republic of China, GB/T23561-2010 Methods for Determining the Physical and Mechanical Properties of Coal and Rock, Standards Press of China, Beijing, China, 2010.

[13] N. I. Muskhelishvili, Some Basic Problems of the Mathematical Theory of Elasticity, P. Noordhoff Ltd, Groningen, Netherlands, 1953.

[14] Q. Z. Wang and X. M. Jia, "Determination of elastic modulus, tensile strength and fracture toughness of brittle rocks by using flattened Brazilian disk specimen," Chinese Journal of Rock Mechanics and Engineering, vol. 21, no. 9, pp. 1285-1289, 2002.

[15] H.-F. Xu, W. Wang, Q. Fang, and W.-B. Wang, "Evolution model of rock plastic strain under cyclic loading," Journal of PLA University of Science and Technology (Natural Science Edition), vol. 13, no. 3, pp. 282-286, 2012.

[16] D. Zheng and N. Ju, "Scanning electronic microscope tests for rock micro-rupture mechanism and fracture characteristic of phyllite," Journal of Engineering Geology, vol. 19, no. 3, pp. 317322, 2011.

[17] X.-B. Yu, Q. Xie, X.-Y. Li, Y.-K. Na, and Z.-P. Song, "Cycle loading tests of rock samples under direct tension and compression and bi-modular constitutive model," Chinese Journal of Geotechnical Engineering, vol. 27, no. 9, pp. 988-993, 2005. 


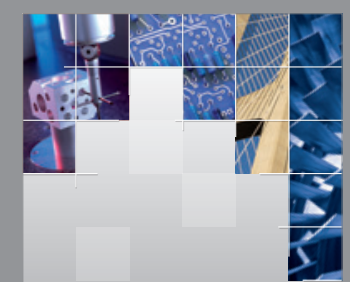

\section{Enfincering}
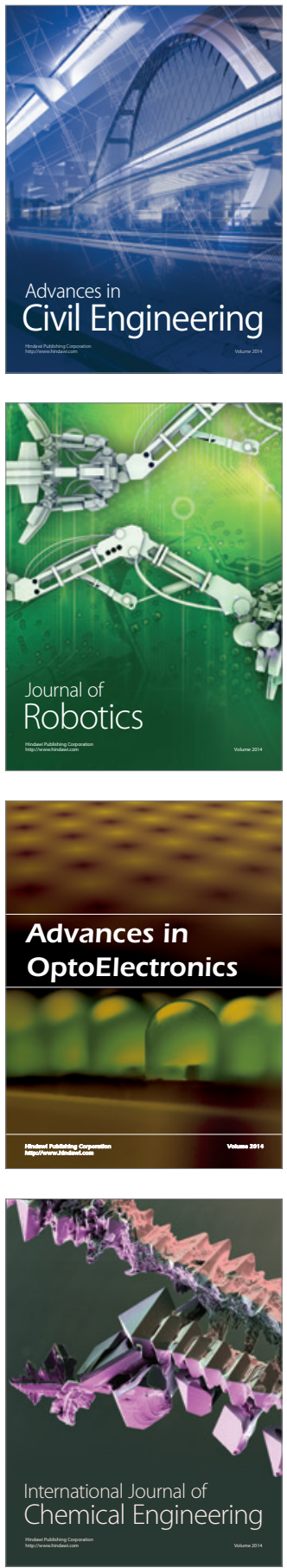

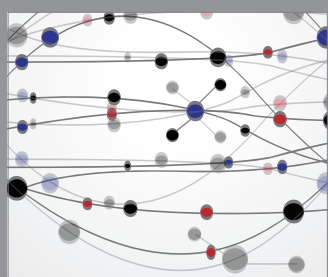

The Scientific World Journal

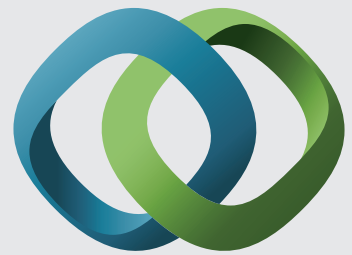

\section{Hindawi}

Submit your manuscripts at

http://www.hindawi.com
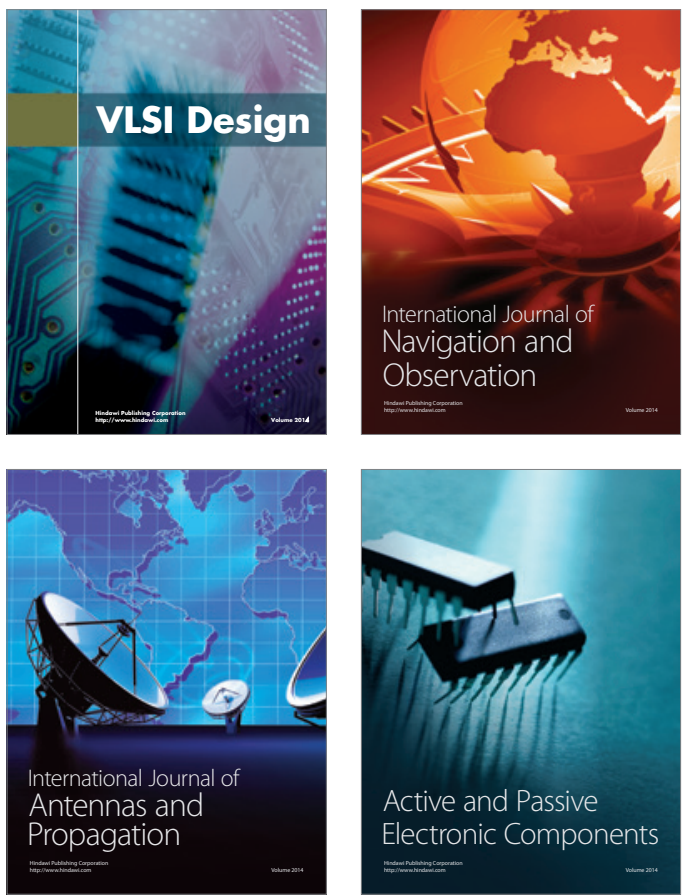
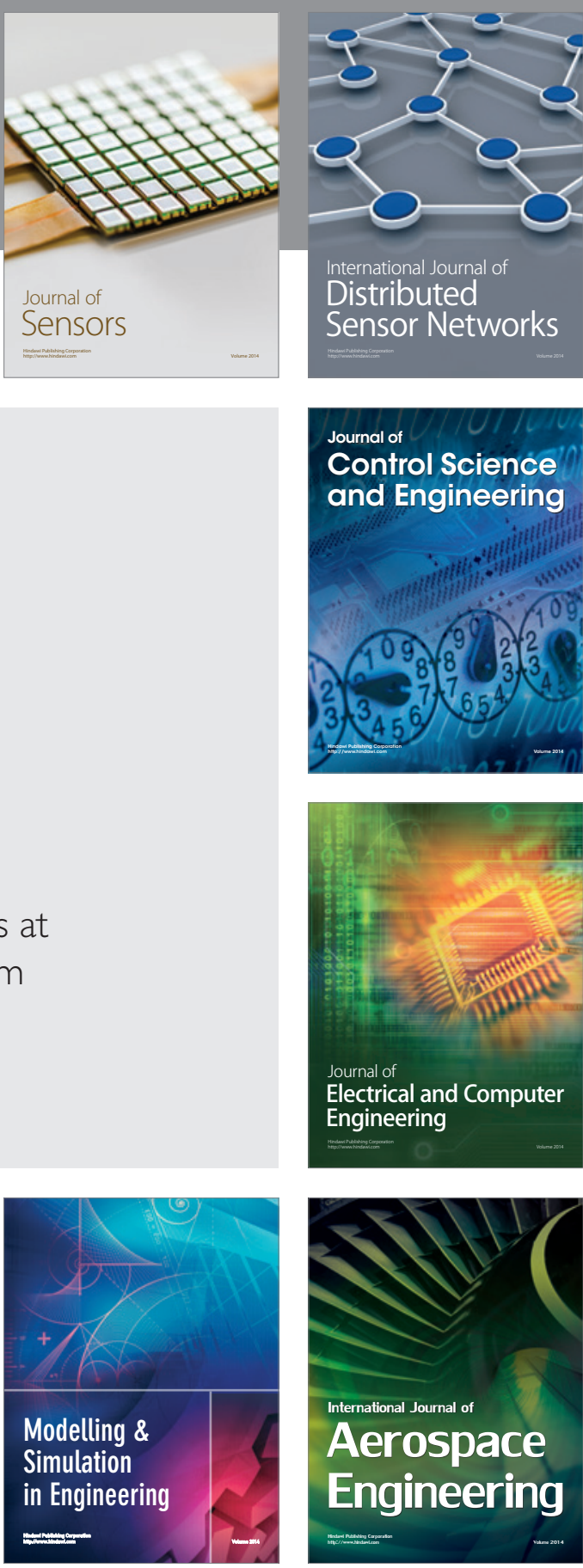

International Journal of

Distributed

Sensor Networks

Journal of

Control Science

and Engineering
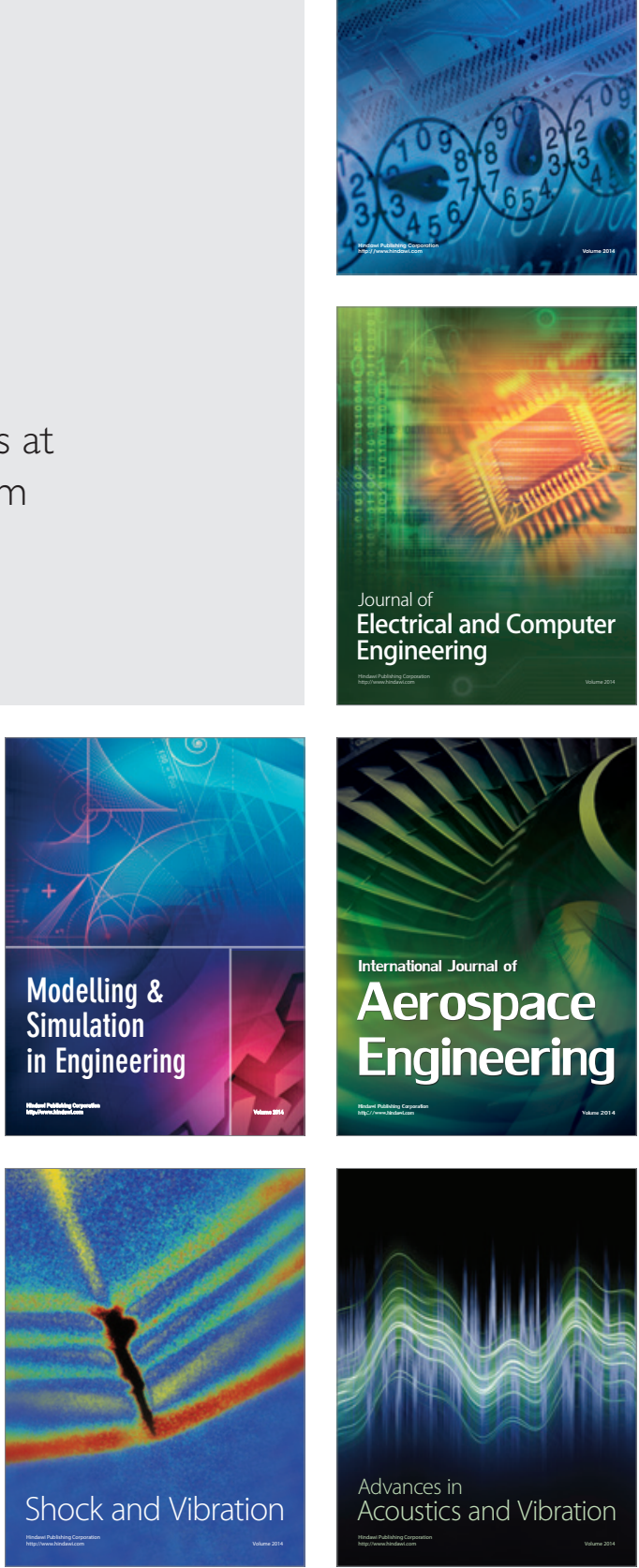